\title{
"You begin to give more value in life, in minutes, in seconds": spiritual and existential experiences of family caregivers of patients with advanced cancer receiving end-of-life care in Brazil
}

\author{
Andrea Carolina Benites ${ }^{1}$ [D $\cdot$ Gary Rodin ${ }^{2,3}$. Érika Arantes de Oliveira-Cardoso ${ }^{1} \cdot$ Manoel Antônio dos Santos $^{1}$
}

Received: 17 July 2021 / Accepted: 18 November 2021 / Published online: 24 November 2021

(๖) The Author(s), under exclusive licence to Springer-Verlag GmbH Germany, part of Springer Nature 2021

\begin{abstract}
Purpose Facing the end of life may trigger significant distress in family caregivers of patients with advanced cancer. However, few studies have addressed the spiritual and existential concerns of these family caregivers in their end-of-life care journey. This study aimed to understand the spiritual and existential experience of family caregivers of patients with advanced cancer facing the end of life in Brazil.

Methods A purposive sample of 16 family caregivers of hospitalized terminally ill cancer patients in Brazil participated in in-depth interviews. Data collection and analysis were based on interpretative phenomenological analysis.

Results Three superordinate themes in their spiritual and existential experience were identified: (i) connectedness through caregiving, personal relationships, and spiritual beliefs; (ii) shifting hope: from death as a possibility to preparation for impending death; (iii) reframing suffering and meaning. For these caregivers, the relationship with the patient and with others, their spiritual beliefs, and hope were significant sources of meaning. Hope was sustained by death avoidance, oscillating with death acceptance and hope that it would occur with comfort. Family caregivers also experienced existential and spiritual suffering in the form of guilt, suppressed emotions, and loneliness.

Conclusion Health care providers should address and support caregivers' spiritual needs and their relationships with the patient and others during end-of-life care and facilitate reflection regarding existential concerns, meaning, and preparation for impending death.
\end{abstract}

Keywords Family caregivers $\cdot$ Neoplasms $\cdot$ Palliative care $\cdot$ Spirituality $\cdot$ Qualitative research $\cdot$ End of life

Andrea Carolina Benites

benites.acb@gmail.com

Gary Rodin

gary.rodin@uhn.ca

Érika Arantes de Oliveira-Cardoso

erikaao@ffclrp.usp.br

Manoel Antônio dos Santos

masantos@ ffclrp.usp.br

1 Psychology Graduate Program, Faculdade de Filosofia, Ciências e Letras de Ribeirão Preto, Universidade de São Paulo, Ribeirão Preto, SP, Brazil

2 Global Institute of Psychosocial, Palliative and End-of-Life Care (GIPPEC), University of Toronto, Toronto, ON, Canada

3 Cancer Experience, Department of Supportive Care, Princess Margaret Cancer Centre, University Health Network,

Toronto, ON, Canada

\section{Background}

Palliative care includes support for family caregivers during the patient's illness and in bereavement [1]. Family caregivers of patients with advanced cancer experience substantial distress during their caregiving experience, heightened by the burden of caregiving and uncertainty related to the course of the disease and expected survival [2]. Family caregivers may experience burden related to depressive symptoms, anxiety, and somatization [3]. Moreover, they may face multiple existential, practical, personal, relational, and social losses related to alterations in their previous relationship with the patient, their social relations, and the anticipated loss of their loved one [2, 4-7]. The burden of care may be particularly great in Brazil, where palliative care services are often limited to inpatient care in hospitals [8]. 
The family member of a patient living with advanced cancer at the end of life may have spiritual needs and existential concerns related to the loss of meaning and to distress about dying and death [9-11]. However, despite these concerns, family caregivers may experience a deep connection with their loved ones and a sense of meaning and purpose through their caregiving $[12,13]$. Indeed, spirituality includes a sense of connectedness to self, others, a higher power, nature, or the sacred $[14,15]$. It has also been described as a dynamic process, which can be triggered by death confrontation [16], that may involve a struggle with questions of meaning, suffering, guilt, hope and despair, values and attitudes, and religious beliefs. Spirituality may be manifest different ways and should be considered in this context, even when the term spirituality is not mentioned [17].

While confrontation with the death of a loved one can trigger existential concerns and distress, it may also facilitate a process called "double-awareness." This term refers to the adaptation to the life-death tension, facing patients with advanced cancer and their family members, in which contemplation of death optimally coexists with life engagement $[18,19]$. Double awareness may also be sustained when family caregivers are dealing with the impending death of a patient with advanced cancer. When there is adequate support, caregiving at the end of life can be a transformative and spiritual experience [20]. However, few studies have drawn attention to the experience of family caregivers providing care to a family member with advanced cancer at the end of life and its connections to spiritual and existential concerns, and there have been no such studies with Brazilian family caregivers.

The present study aimed to understand the spiritual and existential experiences of Brazilian family caregivers of hospitalized patients with advanced cancer facing the end of life.

\section{Methods}

\section{Study design}

A qualitative design was employed to understand the indepth experience of family caregivers facing the end of life of their hospitalized family member. Interpretative phenomenological analysis (IPA), which has been widely used in psychology and health care research [21], was used to allow a deep understanding of participants' personal experience, including their world orientation and construction of meaning [22]. The process of interpretative analysis in IPA [23] includes an initial focus on individual experiences of meaning-making and then comparison with other cases $[22,24]$. The consolidated criteria for reporting qualitative research (COREQ) guided this study to ensure scientific rigor [25]. The study was approved by the Faculty of Philosophy, Sciences, and Letters of Ribeirao Preto at the University of Sao Paulo, Brazil, Research Ethics Committee (CAAE-82845718.2.0000.5407).

\section{Data collection}

Participants were purposively selected based on the family caregiver's relationship with the patient, patients' tumor types, time of diagnosis, and period of hospitalization. Inclusion criteria were as follows: (a) a spouse, relative, or friend who was providing care during the hospitalization of a patient with advanced cancer near the end of life; (b) awareness of the advanced cancer prognosis, with cure no longer the goal of care; and (c) over 18 years of age. Participants were identified by health care providers who worked in a tertiary medical center and a specialized oncology center located in the State of Sao Paulo, Brazil. The researcher discussed with the health care team recruitment criteria of family caregivers and their potential participation in in-depth interviews. These health care providers then provided initial information for potential participants and asked their permission to be approached by the researcher. Eligible participants were invited to participate in the study by the first author (ACB), who provided them with further information about the study. Caregivers who agreed to participate signed a consent form clarifying their voluntary participation in this study. Their confidentiality was preserved using pseudonyms chosen by them. Data collection was performed before COVID-19 pandemic.

The researcher collected field notes following the interviews to register reflexive observations during data collection. Family caregivers were invited to share their caregiving experiences, focusing on spiritual and existential domains, including (1) the experience of accompanying the family member from the time of diagnosis; (2) what is most important to them in their life at the present time; (3) to what extent and in what way their values or priorities in life changed after their loved one's illness and proximity to the end of life; and (4) their values and beliefs at this time in their lives. Data saturation was considered to have been achieved when rich personal accounts and common themes were identified across the sample during data collection and analysis.

\section{Data analysis}

All interviews were transcribed verbatim in Brazilian Portuguese and analyzed using IPA [22], focusing on accounts of participants' experiences. The first author (ACB) reread and re-listened to the recordings several times to be immersed in the data. The transcripts were transferred to NVivo 12 software to organize the data and analytic process. 
The first author then conducted a case-by-case analysis to identify emergent themes and clusters of themes from the initial notes. These included descriptive and interpretative conceptual comments related to the phenomenon of interest, maintaining idiographic characteristics of IPA analysis. The analysis process was traced through audit trail by a second member of the research team (MAS). Thirdly, the research team implemented a cross-case analysis of the 16 transcribed interviews looking for connections, convergences, and divergences among emergent and superordinate themes. Finally, the themes were integrated into a narrative account, which required an active role of the researcher in interpreting and making sense of the data [26]. Considering Yardley's [27] recommendation regarding establishment of validity, the preliminary results were discussed with the supervisor and larger research groups to reconsider emerging themes generated.

\section{Results}

\section{Participants}

Participants were interviewed individually by a female trained psychologist doctoral candidate (first author). All interviews took place in the hospital between June 2018 and March 2019 and were audio-recorded and lasted between 45 and $80 \mathrm{~min}$. Two potential participants refused participation due to their unavailability at that time. In total, 16 family caregivers agreed to participate in the study and all of the interviews were conducted in the hospital during their loved one's hospitalization; all of these caregivers had provided care to these patients in their community before that. All patients died in the hospital, and most of them died in a few days after the interview. Table 1 presents information about the sociodemographic characteristics.

\section{Findings}

Participants described their spiritual and existential experiences during the journey of their loved one's end-of-life care. Three themes emerged: (1) connectedness through caregiving, personal relationships, and spiritual beliefs; (2) shifting hope: from death as a possibility to preparation for impending death; and (3) reframing suffering and meaning (Table 2).

\section{Connectedness through caregiving, personal relationships, and spiritual beliefs}

Connection with caregiving and personal relationships When confronted with the possibility of the imminent death of their loved one, most participants indicated that
Table 1 Family caregiver demographic characteristics

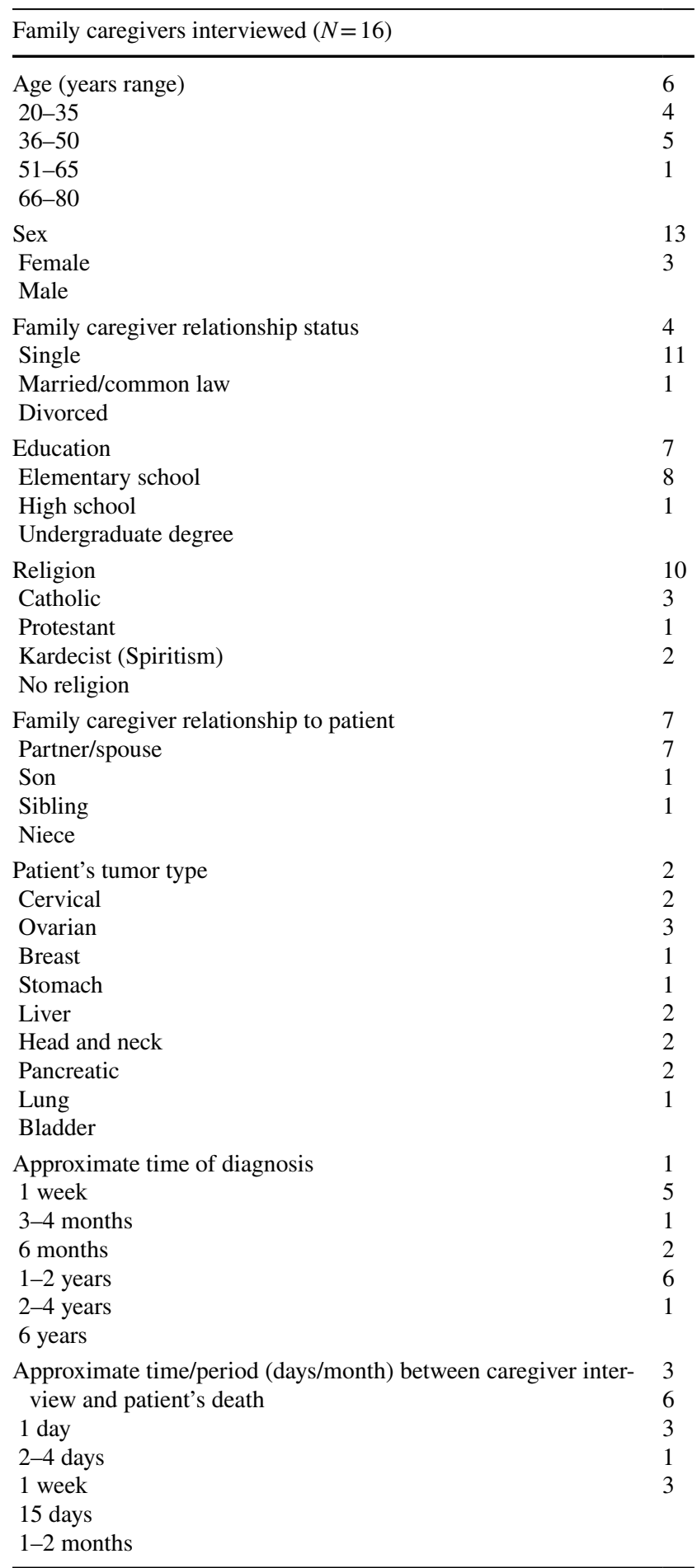

they felt that their presence was imperative during end-oflife care, offering security to the patient through compassionate care. The possibility of being present until the end of life helped them to feel that they could alleviate the suffering of their loved one: 
He calms down a little bit. So, I think that, just from him knowing that I am here, from my presence, he calms down. I think he is aware that I am here, but I don't know how long. I just ask God to help me so that his death be in peace (Maria, spouse).

Although some participants reported conflicts in their family and marital relationships, most felt more emotionally connected and attached to their loved ones in the last days of their lives, through presence and caregiving:

Oh, so... more love with each other. Not that we didn't have it, but we increase the affection more. We already had affection for each other. We see the way ... it seems like I don't know, I don't know how to explain it, but I became more attached to her, more closer than I ever was, but now it has increased. I know she depends on me, so ... I'm always there ... for me, she's everything, I love her. I've always loved her. We didn't open up, you know? (Carlos, spouse).

Spiritual beliefs Most participants believed that they should be strong to deal with the emotional impact of caregiving and the end of life of their loved one. They relied on their belief in a Higher Power, as well as in spiritual practices, such as prayer, for comfort and strength to cope with the impending death of the patient:

It is very difficult ... I don't know, I am Protestant, I believe in God. God is comforting us, you know? God

Table 2 Superordinate themes, themes, and emergent themes

\begin{tabular}{|c|c|c|}
\hline Superordinate themes & Themes & Emergent themes \\
\hline \multirow[t]{2}{*}{$\begin{array}{l}\text { Connectedness through caregiv- } \\
\text { ing, personal relationships, and } \\
\text { spiritual beliefs }\end{array}$} & Connection with caregiving and personal relationships & $\begin{array}{l}\text { Strengthening personal relationships } \\
\text { Compassion } \\
\text { Caregiving as a mission in life } \\
\text { To be present until death } \\
\text { Express and share their feelings } \\
\text { Having their suffering validated by others } \\
\text { Presence } \\
\text { Be strong to be able to provide care }\end{array}$ \\
\hline & Spiritual beliefs & $\begin{array}{l}\text { Individual connection with God } \\
\text { Faith in God provides strength, confidence, and } \\
\quad \text { comfort } \\
\text { Prayer } \\
\text { Resignation toward God } \\
\text { Hope in life after death }\end{array}$ \\
\hline \multirow[t]{2}{*}{$\begin{array}{l}\text { Shifting hope: from death as a } \\
\text { possibility to preparation for } \\
\text { impending death }\end{array}$} & Death proximity and avoidance & $\begin{array}{l}\text { Unexpected disease progression } \\
\text { Confrontation with death and its inevitability } \\
\text { Realization of the end of life } \\
\text { Patient's realization of death proximity } \\
\text { Significant losses in the life story } \\
\text { Hope for recovery, hope for a miracle }\end{array}$ \\
\hline & $\begin{array}{l}\text { Hope shifted to focus on death acceptance and death } \\
\text { preparation }\end{array}$ & $\begin{array}{l}\text { Acceptance of the impending loss as alleviation of } \\
\text { suffering } \\
\text { Facing the transience of life and impermanence } \\
\text { Hope focused on death as the end of suffering } \\
\text { Focus on comfort measures and relieve of suffering }\end{array}$ \\
\hline \multirow[t]{2}{*}{ Reframing suffering and meaning } & Existential and spiritual suffering & $\begin{array}{l}\text { Guilt and regret } \\
\text { Guilt for turning away from the Church } \\
\text { Helplessness } \\
\text { Impotence } \\
\text { Uncertainty about the future } \\
\text { Self-neglect } \\
\text { Patient's suffering increases caregiver's distress } \\
\text { Loneliness } \\
\text { Suppression of feelings }\end{array}$ \\
\hline & Finding meaning and purpose in suffering and life & $\begin{array}{l}\text { Illness and suffering as source of meaning } \\
\text { Facing illness as a divine ordeal } \\
\text { Maturity and learning for life } \\
\text { Legacy } \\
\text { Changes and personal growth } \\
\text { Reframing life purpose and priorities } \\
\text { Living the present moment }\end{array}$ \\
\hline
\end{tabular}


is giving wisdom so that we can deal with this situation (Beatriz, son).

Some participants mentioned their belief in life after death as a source of comfort, considering life as a passage, as a means to dealing with finiteness:

It comforts me to know that there is a life afterwards, but I have plenty of reasons not to believe this, because I don't have proof. But I prefer to believe that there is something because it comforts me, even though I know that... I am more certain that there isn't, I want to believe that there is something because it comforts me. It comforts me to know that after I die, I won't be gone. I will remain, even if only in memory or even as energy (Pedro, son).

Although they tried to be strong and to rely on their faith, most participants pointed out the importance of receiving emotional support from health care providers during their journey to manage their emotional distress:

I do not know, should have a support for us. Someone who comes and gives attention. There isn't (that). I think that these hours are the hours that there has to be someone to help us calm down, that we ... our nervousness is too much of a concern (Carlos, spouse).

\section{Shifting hope: from death as a possibility to preparation for impending death}

Death proximity and avoidance Our participants experienced an oscillation between avoidance and accepting the likelihood of imminent death based on the progression of the disease. Most participants reported that the physical and emotional burden on them intensified with the physical deterioration of the patient and progression of the dying process:

And now it is also very intense, because ... as she is very debilitated, more than before, so much that she is hospitalized because we cannot cope, there are things we cannot do, we wear out a lot, our body cannot handle it (Pedro, son).

Participants reported that their hope shifted when faced with the impossibility of cure and progression of the dying process. Some continued to avoid considering the possibility of imminent death as the contemplation of this reality seemed to be painful for them. They tried to maintain their hope in the search for a "miracle" or clinical improvement:

More time with me, to stay with me. I want her healing, you know? See that she doesn't have anything else, you know? I feel like this inside me, I know she is, but for me she has nothing else, you know. I know she is, I know she can go [death], but I don't believe it. I know she will, but ... do you know that desire we don't want to lose? (Carlos, spouse).

Hope shifted to focus on death acceptance and death preparation With increasing proximity to the end of life, most participants shifted their hope to focus on the acceptance of death and preparation for this inevitability.

If I leave and it happens, I will regret it, so I want to be there on time. This is what I want. I want to see him go. I know I'm going to suffer a little, but then ... I got used to it, I already gave it to God, that God will help us, that he takes him in peace. And I'm not going to despair. I'm not going to scream, I'm not going to cry, because that's no use anymore (Sebastiana, spouse).

At this time, participants reported that they focused on comfort measures, instead of on invasive measures to relieve the patient's suffering at the end of life. They indicated that their hope and faith was maintained by focusing on death as the end of patient's suffering:

I am calm. If I tell you as soon as I am ... that I don't want her to go, I am lying. I want my mom to rest, because she was always very full of life, you know? [...], but I don't think it has more to do with faith. I think it has more to do with reality. Suddenly her healing is now on the spiritual side, getting rid of this suffering of the flesh (Anjo, son).

Some participants considered that such experiences drew their attention to the transience and impermanence of life:

Nothing lasts forever. Your pain, your headache, your ... your leg pain ... just our old age that will arrive. It's not forever either, you will leave too. Isn't it? (Lucia, spouse).

\section{Reframing suffering and meaning}

Existential and spiritual suffering Some participants reported feeling guilty about not being present in the last hours of a family member's life. Others experienced guilt about turning away from religious practices:

I must leave ... So, it hurts, but I go with the feeling that what I could do I did, what I could take care of, I took care, until her last breath. And I think it will be worse if I stay here, it will be worse (Fernanda, son).

Look, I am evangelical, and although I am not frequent. The church I attend is on the side of my house. I ended up pulling away a bit, you know. Although I 
should not, but because of the rush and stuff (Mariana, son).

Participants experienced more emotional distress when patients' symptoms were not well controlled. In general, they tried to suppress their feelings when they were with the patient, to avoid showing weakness and to protect them from additional suffering. However, they felt often helpless and powerless in their journey, facing many uncertainties:

So, he's aware, I get upset, there are times when we stop, and we cry, but I don't want him to suffer. There was a night when he asked us for poison, when he asked us to give him poison because he couldn't stand it anymore [...] the suffering. If only he wasn't so sick the way he is, you know? The hardest part is this: watching him suffer (Idalina, wife).

Very sad to see the person you like to suffer without you being able to do anything. [choro] (Isabelle, niece).

Finding meaning and purpose in suffering and life Participants reported that confronting the possibility of the death of their loved one death triggered reflections on the meaning of their suffering and of life, with some viewing the patient's illness as a divine ordeal that was visited on them. Participants often reported that facing death and dying precipitated a reordering of their priorities in life:

You begin to give more value in life, in minutes, in seconds. You end up appreciating small things (Fernanda, son).

Despite the emotional distress experienced, most participants indicated that they experienced maturation and personal growth as a result of their caregiving experience: "Experiencing this made me think a lot and thinking a lot transformed me, deconstructed many things, many paradigms" (Pedro, son). As part of that process, they considered the legacy of their loved one and the value of the life that they had lived. They also described the deeper connection that developed between them and the patient during the caregiving process, and the importance of living the present moment, while the loved one is still alive:

It is a popular saying that if we don't have faith, one day we will learn through pain (Vitoria, daughter).

I know now, what I'm going through now, I don't know what I'm going to get through tomorrow and half an hour, an hour, until late, I don't know what I'm going to get through, but for now, I'm here, I'm focused on him, I am living now. This moment (Maria, spouse).

\section{Discussion}

This study aimed to understand the spiritual and existential experiences of family caregivers of patients with advanced cancer when facing end-of-life care. We identified three overarching themes in their reports: spirituality interconnected with caregiving and personal relationships; hope and meaning linked to spiritual beliefs; existential and spiritual suffering when facing death proximity.

Our findings are consistent with other studies of family caregivers showing that spirituality plays a significant role in sustaining hope, comfort, and strength [28, 29]. Their physical presence while the patient was confronting death helped family caregivers to process feelings of powerlessness and anticipatory grief, which corroborates the findings of other studies [30,31]. Our results also highlighted that connectedness was experienced through caregiving, and that personal relationships seemed to be transformative in their existential and spiritual experience $[13,32]$. Connection with the family member played an important role in spirituality and the meaning of caregiving for the patient with advanced cancer, as reported by others [14, 33]. During the last stage of their journey, hope shifted from the possibility that a miracle would occur to hope for a good death without pain and as the end of suffering. This result is consistent with that of other studies [30,34], particularly related to the importance of symptom control [35] and the place of death in their quality of death and dying [36].

The experience of witnessing physical decline and the irreversibility of the illness in the patient triggered anticipatory feelings of loss in caregivers. They often felt ambivalent about the survival of the patient, with both the hope for death as the end of the patient's suffering and the hope for the prolongation of their life. Another study similarly identified this ambivalence in the anticipatory grieving of caregivers [6]. Our results are also consistent with other research highlighting that family caregivers may experience significant spiritual, existential, and emotional suffering in their journey toward the end of life [7, 9, 20]. We found that caregivers tried to suppress their feelings to demonstrate strength to the patient, but, as in other studies $[6,28,30$, 34], feelings of loneliness and helplessness were common. These findings suggest that family caregivers would benefit from having a safe space to reflect about the mortality of the patient and themselves and that health care providers should receive educational training on how to manage existential and spiritual distress of patients and their family members $[4,10]$.

Although family caregivers experienced considerable suffering near the end of life, they also experienced significant spiritual and existential transformation through caregiving and their end-of-life experiences [32]. Their sense of 
meaning and purpose and priorities in life changed when dealing with the impending loss. This is consistent with other research demonstrating that confronting death can lead to an existential awakening, as it enhances existential questions and concerns related to finiteness, life, and death $[32,37]$. Our findings also showed that the concept of double awareness can be applied to family caregivers of cancer patients facing end of life, as they tried to find a balance in engagement in life with the patient, while also considering the anticipated loss in the face of impending death [18, 19].

\section{Strengths and limitations}

A strength of this study was the multidisciplinary research team that enriched data analysis from multiple perspectives. However, our participants were primarily Christians, which may limit in the generalizability of findings to other religious groups. Qualitative interviews provided access to their indepth experiences of spirituality in caregiving. The initial questions or probes did not specifically ask about religion or spirituality, although this emerged in all of the interviews. Our study also did not examine caregiving experiences earlier in the course of the disease. Longitudinal research is needed to understand the in-depth experience of caregivers over the course of their journey, including in bereavement.

\section{Clinical implications and conclusion}

Attention to existential and spiritual issues in family caregivers facing end of life care is essential for an oncology interdisciplinary health care team and should be assessed and managed by health care providers. This should include consideration of the family caregiver's personal relationship with the patient and presence at the end of life as a source of meaning for both the patient and the caregiver. Further research is needed to determine the optimal nature and effectiveness of individual, couple-based, and group psychotherapeutic and spiritual interventions for the caregivers of patients with advanced cancer.

Acknowledgements We acknowledge contributions by Eryn Tong and the Qualitative Research Seminar team of the Research Division, Department of Supportive Care at the Princess Margaret Cancer Centre, University Health Network, for comments on the manuscript.

Author contribution ACB, GR, EAO, and MAS made substantial contributions to conception and design, or acquisition of data, or analysis and interpretation of data; involved in drafting the manuscript or revising it critically for important intellectual content; and given the final approval of the version to be published. Each author should have participated sufficiently in the work to take public responsibility for appropriate portions of the content; and agreed to be accountable for all aspects of the work in ensuring that questions related to the accuracy or integrity of any part of the work are appropriately investigated and resolved.

Funding This study received funding through a research fellowship abroad and a research fellowship granted to the first author by the Sao Paulo Research Foundation (FAPESP) grant \#2019/02134-0 and \#2017/26542-5. MAS were supported by the National Council for Scientific and Technological Development (CNPq).

Data availability The data that support the findings of this study are available from the corresponding author upon reasonable request.

\section{Declarations}

Ethics approval All procedures performed in studies involving human participants were in accordance with the ethical standards of the institutional and/or national research committee and with the 1964 Helsinki Declaration and its later amendments or comparable ethical standards. The study was approved by the Faculty of Philosophy, Sciences, and Letters of Ribeirao Preto at the University of Sao Paulo, Brazil, Research Ethics Committee (CAAE-82845718.2.0000.5407).

Consent to participate Informed consent was obtained from all individual participants included in the study.

Consent for publication Participants signed informed consent regarding publishing their data.

Conflict of interest The authors declare no competing interests.

\section{References}

1. Radbruch L, De Lima L, Knaul F et al (2020) Redefining palliative care: a new consensus-based definition. J Pain Symptom Manage 60:754-764. https://doi.org/10.1016/j.jpainsymman.2020.04.027

2. Stajduhar KI (2013) Burdens of family caregiving at the end of life. Clin Invest Med 36:121-126. https://doi.org/10.25011/cim. v36i3.19722

3. Delalibera M, Coelho A, Frade P, Barbosa A, Leal I (2020) Caregiving and bereavement in palliative care: a cross-cultural study between Brazil and Portugal. Transcult Psychiatry 57:445-454. https://doi.org/10.1177/1363461520909596

4. Best M, Aldridge L, Butow P, Olver I, Webster F (2015) Conceptual analysis of suffering in cancer: a systematic review. Psychooncology 24:977-986. https://doi.org/10.1002/pon.3795

5. Braun M, Hales S, Gilad L, Mikulicer M, Rydall A, Rodin G (2012) Caregiving styles and attachment orientations in couples facing advanced cancer: caregiving style and attachment orientations in couples facing cancer. Psychooncology 21:935-943. https://doi.org/10.1002/pon.1988

6. Coelho A, de Brito M, Teixeira P, Frade P, Barros L, Barbosa A (2020) Family caregivers' anticipatory grief: a conceptual framework for understanding its multiple challenges. Qual Health Res 30:693-703. https://doi.org/10.1177/1049732319873330

7. Nissim R, Hales S, Zimmermann C, Deckert A, Edwards B, Rodin G (2017) Supporting family caregivers of advanced cancer patients: a focus group study. Fam Relat 66:867-879. https://doi. org/10.1111/fare.12291

8. Valentino TCO, Paiva CE, Hui D, de Oliveira MA, Paiva BSR (2019) Impact of palliative care on quality of end-of-life care 
among Brazilian patients with advanced cancers. J Pain Symptom Manage 59:39-48. https://doi.org/10.1016/j.jpainsymman.2019. 08.021

9. Applebaum AJ, Kryza-Lacombe M, Buthorn J, DeRosa A, Corner G, Diamond EL (2016) Existential distress among caregivers of patients with brain tumors: a review of the literature. Neurooncol Pract 3:232-244. https://doi.org/10.1093/nop/npv060

10. Melin-Johansson C, Henoch I, Strang S, Browall M (2012) Living in the presence of death: an integrative literature review of relatives' important existential concerns when caring for a severely ill family member. Open Nurs J 6:1-12. https://doi.org/10.2174/ 1874434601206010001

11. Yalom ID (1980) Existential psychotherapy. Basic Books, New York

12 Lalani N, Duggleby W, Olson J (2018) Spirituality among family caregivers in palliative care: an integrative literature review. Int $\mathbf{J}$ Palliat Nurs 24:80-91. https://doi.org/10.12968/ijpn.2018.24.2.80

13. Lalani N, Duggleby W, Olson J (2019) Rise above: experiences of spirituality among family caregivers caring for their dying family member in a hospice setting in Pakistan. J Hosp Palliat Nurs 21:422-429. https://doi.org/10.1097/NJH.0000000000000584

14. Puchalski CM, Vitillo R, Hull SK, Reller N (2014) Improving the spiritual dimension of whole person care: reaching national and international consensus. J Palliat Med 17:642-656. https://doi.org/ 10.1089/jpm.2014.9427

15. Weathers E, McCarthy G, Coffey A (2016) Concept analysis of spirituality: an evolutionary approach. Nurs Forum 51:79-96. https://doi.org/10.1111/nuf.12128

16. Vachon M, Fillion L, Achille M (2009) A conceptual analysis of spirituality at the end of life. J Palliat Med 12:53-59. https://doi. org/10.1089/jpm.2008.0189

17. Best M, Leget C, Goodhead A, Paal P (2020) An EAPC white paper on multi-disciplinary education for spiritual care in palliative care. BMC Palliat Care 19:9. https://doi.org/10.1186/ s12904-019-0508-4

18. Colosimo K, Nissim R, Pos AE, Hales S, Zimmermann C, Rodin G (2018) "Double awareness" in psychotherapy for patients living with advanced cancer. J Psychother Integr 28:125-140. https://doi. org/10.1037/int000007819

19. Rodin G, Zimmermann C (2008) Psychoanalytic reflections on mortality: a reconsideration. J Am Acad Psychoanal Dyn Psychiatry 36:181-196. https://doi.org/10.1521/jaap.2008.36.1.181.20

20. Benites AC, Rodin G, Leite ACAB, Nascimento LC, Dos Santos MA (2021) The experience of spirituality in family caregivers of adult and elderly cancer patients receiving palliative care: a metasynthesis. Euro J Cancer Care 30:e13424. https://doi.org/10.1111/ ecc. 13424

21. Peat G, Rodriguez A, Smith J (2019) Interpretive phenomenological analysis applied to healthcare research. Evid Based Nurs 22:7. https://doi.org/10.1136/ebnurs-2018-103017

22. Smith JA, Flowers P, Larkin M (2009) Interpretative phenomenological analysis: theory, method and research. Sage, Thousand Oaks

23. Larkin M, Watts S, Clifton E (2006) Giving voice and making sense in interpretative phenomenological analysis. Qual Res Psychol 3:102-120. https://doi.org/10.1191/1478088706qp062oa

24 Tombolato MA, Santos MA (2020) Análise Fenomenológica Interpretativa (AFI): fundamentos básicos e aplicações em pesquisa. Rev Abordagem Gestal 26:293-304. https://doi.org/10. 18065/2020v26n3.5

25. Tong A, Sainsbury P, Craig J (2007) Consolidated criteria for reporting qualitative research (COREQ): a 32-item checklist for interviews and focus groups. Int J Qual Health Care 19:349-357. https://doi.org/10.1093/intqhe/mzm042

26. Smith JA (2015) Qualitative psychology: a practical guide to research methods. SAGE, London

27. Yardley L (2000) Dilemmas in qualitative health research. Psychol Health 15:215-228. https://doi.org/10.1080/08870440008400302

28. Arian M, Younesi SJ, Khanjani MS (2017) Explaining the experiences and consequences of care among family caregivers of patients with cancer in the terminal phase: a qualitative research. Int J Cancer Manag 10:e10753. https://doi.org/10.5812/ijcm. 10753

29. Paiva BSR, Carvalho AL, Lucchetti G, Barroso EM, Paiva CE (2015) "Oh, yeah, I'm getting closer to god": spirituality and religiousness of family caregivers of cancer patients undergoing palliative care. Support Care Cancer 23:2383-2389. https://doi. org/10.1007/s00520-015-2604-1

30. Totman J, Pistrang N, Smith S, Hennessey S, Martin J (2015) 'You only have one chance to get it right': a qualitative study of relatives' experiences of caring at home for a family member with terminal cancer. Palliat Med 29:496-507. https://doi.org/10.1177/ 0269216314566840

31. Lima CPdL, Machado MdA (2018) Cuidadores Principais Ante a Experiência da Morte: Seus Sentidos e Significados. Psicol Ciênc Prof 38:88-101. https://doi.org/10.1590/1982-3703002642015

32. Vachon M (2020) "It made me more human": existential journeys of family caregivers from prognosis notification until after the death of a loved one. J Palliat Med 23:1613-1618. https://doi.org/ 10.1089/jpm.2019.0689

33. Maiko S, Johns SA, Helft PR, Slaven JE, Cottingham AH, Torke AM (2019) Spiritual experiences of adults with advanced cancer in outpatient clinical settings. J Pain Symptom Manage 57:576586. https://doi.org/10.1016/j.jpainsymman.2018.11.026

34. Sutherland N (2009) The meaning of being in transition to end-oflife care for female partners of spouses with cancer. Palliat Support Care 7:423-433. https://doi.org/10.1017/S14789515099904 35

35. Juarez G, Branin JJ, Rosales M (2014) The cancer caregiving experience of caregivers of Mexican ancestry. Hisp Health Care Int 12:120-129. https://doi.org/10.1891/1540-4153.12.3.120

36. Hales S, Chiu A, Husain A, Braun M, Rydall A, Gagliese L, Zimmermann C, Rodin G (2014) The quality of dying and death in cancer and its relationship to palliative care and place of death. J Pain Symptom Manage 48:839-851. https://doi.org/10.1016/j. jpainsymman.2013.12.240

37. Yalom ID (2008) Staring at the sun: overcoming the terror of death. Jossey-Bass, San Francisco

Publisher's note Springer Nature remains neutral with regard to jurisdictional claims in published maps and institutional affiliations. 